\title{
Métodos de análise no estudo de representações sociais dos estudantes: o acesso ao Ensino Superior na UFRN
}

Ridha Ennafaa

Université de Paris 8 | Vincennes à Saint Denis

\section{Resumo}

O artigo apresenta os resultados de uma investigação sobre o acesso à universidade e as trajetórias dos estudantes. Analisam-se particularmente as Representações Sociais da Universidade (UFRN) dos estudantes que concluem o Ensino Médio. Procura-se compreender, a partir dessas representações, a visão que os candidatos do ensino público têm da UFRN no momento do vestibular. A complementaridade dos resultados, junto a outros dados procedentes de abordagens quali-quantitativas, sublinha o valor heurístico de tal abordagem, combinando as informações para integrá-las em estudos longitudinais, que levam em conta os percursos e as perspectivas dos jovens ingressantes na universidade.

Palavras-chave: Representações sociais. Educação superior no Brasil. Metodologia de pesquisa.

\section{Analysis methods for the study of students' social representations: access to Higher Education in UFRN}

\section{Abstract}

The paper presents results of a research on the access to university and the students' trajectories. It particularly analyses the university (UFRN) Social Representation of the high school students. It tries to understand from these representations the vision of the candidates from public education about the university at the University entrance exam moment. The complementarity of the results with other quali-quantitative data underline the heuristic value of such approach combining the information to integrate them in longitudinal studies that take into account the trajectories and the perspectives of young people entering through university.

Keywords: Social representations. Higher education in Brazil. Research methodology. 


\section{Métodos de análisis en el estudio de las representaciones sociales de los estudiantes: el acceso al Enseñanza Superior a la UFRN}

\section{Resumen}

El artigo presenta los resultados de una investigación sobre el acceso a la universidad y las trayectorias estudiantiles. Analizase particularmente las Representaciones Sociales de la Universidad (UFRN) de los estudiantes que concluyen la Enseñanza Media. Intentase comprehender, a partir de esas representaciones, la visión de los candidatos de la enseñanza pública sobre la universidad en el momento del vestibular. La complementariedad de los resultados junto con otros datos quali-quantitativos señala el valor heurístico de tal abordaje, combinando las informaciones para intégralas en estudios longitudinales que llevan en cuenta los recorridos y las perspectivas de los jóvenes ingresantes en la universidad.

Palabras-claves: Representaciones sociales. Educación superior en Brasil. Metodología de pesquisa.

\section{Introdução}

Este artigo apresenta os resultados que se inscrevem no quadro de uma pesquisa mais ampla sobre o acesso à universidade, especialmente sobre as trajetórias dos estudantes que nela ingressam. Além desses resultados, destacam-se os métodos de análise de dados empíricos sobre as condições de vida e de estudos dos estudantes e seus percursos de estudo. No quadro desse artigo, escolhi situar a problemática sobre as questões do acesso ao ensino superior no Brasil, estudando o caso da Universidade Federal do Rio Grande do Norte (UFRN).

A problemática trata particularmente do acesso dos jovens oriundos dos estabelecimentos públicos do ensino médio no Brasil na última década (2000-20 1 1). O principal questionamento está centrado nos elementos que nos ajudariam a melhor compreender o momento da transição do ensino médio para a universidade, a fim de identificar os fatores que ainda bloqueiam o acesso à educação superior para os jovens. Os sinais desse bloqueio podem ser vistos no nível baixo da escolarização de ensino superior observado na faixa etária 18-24 anos, na estagnação da evolução dos inscritos no ensino 
médio desde os anos 2000 e numa seleção sempre elevada para ingressar nas universidades federais, o que parece colocar em questão a causa da democratização, assim como a inclusão de um número maior de jovens na educação pública de qualidade. A massificação do ensino superior que se observa em escala mundial, associada a um crescimento da demanda social por ensino superior, parece estar paralisada no Brasil.

Esse fenômeno de renúncia em grande escala dos concluintes do ensino médio em se candidatarem às universidades federais certamente preocupa os pesquisadores, assim como os responsáveis das políticas de ampliação do acesso à educação superior nas universidades federais para os jovens da rede pública. Logo, é preciso investigar a imagem da universidade em geral e particularmente as representações dos estudos superiores na universidade federal, notadamente para os alunos concluintes do Ensino Médio. Procuro, então, analisar o que nos falam a respeito disso os jovens, candidatos ou não, que querem entrar na universidade.

Essas representações são consideradas como os elementos susceptíveis de efeitos: tomada de posição, decisão, julgamentos, condutas, atitudes, opiniões. Alguns teóricos das representações sociais as consideram como "[...] variáveis independentes [...]", em uma relação causal e de determinações de efeitos (MOLINER; RATEAU; COHEN, 2002, p. 33). Para outros autores, especialmente próximos de Willem Doise, as representações sociais são os princípios organizadores das relações simbólicas entre os atores sociais: "[...] se trata assim de princípios relacionais que estruturam as relações simbólicas entre indivíduos e grupos, constituindo ao mesmo tempo um campo de trocas simbólicas e uma representação desse campo" (DOISE, 1990, p. 248).

Sem me colocar exclusivamente nesta perspectiva, gostaria de apresentar os resultados obtidos com abordagens metodológicas múltiplas e complementares, particularmente aquelas utilizadas por diversos autores do campo das representações sociais (RATEAU; ROUQUETTE, 1998; RATEAU, 2004; ROUQUETTE, 2000; ABRIC, 1994, 2003; JODELET, 1989; DOISE, CLEMENCE, LORENZI-CIOLDI, 1992). Assim, a análise epistemológica, teórica e empírica questiona, de forma inseparável, um conjunto de aplicações dos diversos métodos de análise de dados.

A universidade, especificamente a UFRN, pode ser ela mesma um objeto de representação social? Para responder a isso, Moliner (1993) propõe cinco critérios para uma validação: ele deve ser importante para os indivíduos 
pelo seu status social; ele deve ser um sujeito de comunicação entre os indivíduos; ele deve servir como objeto de um investimento; ele deve se inserir em uma dinâmica social; e, enfim, deve haver a seu respeito uma falta de ortodoxia. Penso, então, que não há nenhum obstáculo para esse estudo, pois a universidade, enquanto objeto de representações sociais, tem amplamente seu lugar no espaço de estudo das representações sociais que apresenta Denise Jodelet (1989). Essa reflexão é uma indicação sobre o lugar que a universidade tem como instituição social no Nordeste brasileiro.

Nossas interrogações metodológicas se inscrevem mais, dentro da abordagem teórica do campo de estudos das representações sociais que fazem referência às variações individuais (DOISE, 1990), do que da abordagem estrutural da teoria do núcleo central. A abordagem dinâmica dos princípios organizadores, geradores das representações, trata das variações individuais e de sua ancoragem nas realidades coletivas. As representações sociais são construções criadas nas dinâmicas do campo social; nelas, os estudantes disputam, no processo de comunicação, sua contribuição para a constituição das representações sociais da universidade. Assim, pode-se pensar em tentar reconstituir os princípios organizadores comuns aos indivíduos, as

14 relações com os valores sociais e coletivos.

Se a abordagem estrutural postula, por exemplo, a existência de uma representação social da universidade (UFRN) que é compartilhada com os alunos do ensino médio, então é preciso investigar os componentes e suas dimensões independentemente dos indivíduos. Nesse caso, a abordagem da teoria dos princípios organizadores vai se apoiar sobre as "divergências interindividuais" para identificar os princípios que organizam a representação: "[...] em outros termos, toda representação é aqui percebida como um conjunto de posicionamentos divergentes a respeito de certo número de princípios gerais que constituem a ossatura de uma representação" (RATEAU, 2004, p. 81 ).

Interrogando-me sobre as evoluções do acesso ao ensino superior no Brasil, particularmente na UFRN no decorrer do período recente $(2000$ a 2010), ficou evidenciado que, apesar das novas políticas favorecendo uma democratização da educação superior para os jovens brasileiros do ensino médio público, desigualdades muito grandes continuam sendo observadas. Apesar dos esforços e das medidas tomadas para os jovens das escolas públicas, esses "esperados" não chegaram às universidades: a faixa etária de 18-24 anos é pouco presente e menos ainda nas universidades federais, que 
são mais seletivas, e, cúmulo dos paradoxos, é entre os jovens das classes socioeconômicas mais favorecidas, estudando na rede privada, que continuamos a observar as taxas de admissão mais elevadas. Então, os estudantes das categorias sociais desfavorecidas na rede pública têm menos sucesso. E se desejarem, apesar de tudo, prosseguir no ensino superior, eles se dirigem para as faculdades do ensino superior privado.

Paralelamente a essa primeira constatação brutal, alguns elementos podem nuançar esse quadro, mostrando sinais da complexidade das estratégias investidas pelos alunos do ensino público, notadamente em suas persistências para quererem entrar na UFRN. Para refinar as observações no ingresso na UFRN, gostaria de destacar a necessidade de levar em conta os estudos longitudinais sob todas as suas formas. Porém, deve-se considerar nesse contexto um fenômeno mais importante desde o começo dos anos 2000: a situação do ensino médio brasileiro com a quase estagnação da evolução de inscritos do ensino médio público e privado, o que parece colocar em questão a política de expansão das universidades desde então. Uma análise afinada dos dados disponíveis ${ }^{1}$ indica que, por falta de candidatos oriundos do ensino médio, a política de massificação de uma educação superior pública de qualidade é colocada em questão, se não forem tomadas medidas no nível do ensino médio público.

De fato, a desaceleração e a quase estagnação das inscrições nos estabelecimentos de ensino médio revelam, de um lado, o evidente desinteresse dos jovens, em sua maioria pertencendo às classes populares, para continuar os estudos superiores em geral e menos ainda em uma universidade federal, e, de outro lado, um grande número de abandono dos estudos antes da conclusão do ensino médio, porque o modelo de ensino proposto apareceria sem objetivos claramente definidos, sem identidade e no limite sem perspectivas para esses jovens. Cristovão Buarque, ex-ministro da educação, utiliza o termo de "deseducação" e enumera todos os encadeamentos das consequências desastrosas que isso tem para o Brasil em termos de desenvolvimento (BUARQUE, 2011 ).

É a partir desse "julgamento" bastante severo sobre o ensino médio que me questiono sobre as "representações" da universidade que podem ter os jovens da rede pública. As representações são tomadas, em um primeiro momento, como um conjunto de atitudes, de opiniões e de imagens que podem no revelar as enquetes, ainda raras sobre o assunto, entre esses 
estudantes, aqueles que se candidatam e aqueles que renunciam a se candidatar ao ingresso no ensino superior. Algumas informações relativas a esse tipo de questões já existem nos questionários dos candidatos ao vestibular da UFRN, outros dados foram recolhidos a partir de enquetes de terreno em uma amostra representativa dos alunos do ensino médio dos estabelecimentos públicos de Natal$^{2}$.

\section{Os candidatos do vestibular: perfis comparados e tipologias dos candidatos dos estabelecimentos públicos}

Nos questionamentos sobre as representações da UFRN e do ensino superior pelos estudantes dos anos finais do ensino médio público, utilizo duas fontes de informações. A primeira é de tipo institucional, os dados dos questionários dos vestibulandos à UFRN desde o ano 2000 até 2011 , um conjunto de 253.325 candidatos, entre os quais os aprovados, que representam mais de 52.000 estudantes inscritos nesta universidade ${ }^{3}$. A segunda fonte é uma enquete realizada com os alunos de uma vintena de estabelecimentos públicos

16 do município de Natal, em uma amostra de mais de 2000 alunos dos anos finais do ensino médio público ${ }^{4}$.

Para melhor compreender o que levou os estudantes dos anos finais do ensino médio público a escolher ingressar na UFRN pelo vestibular, se abordam, em um primeiro momento, os resultados da análise secundária dos dados as enquetes do processo seletivo (PS). Essas informações estão disponíveis no Observatório da Vida do Estudante Universitário (OVEU) da UFRN. Esses dados cobrem o período de 2000 a 201 1, que corresponde a transformações importantes no sistema de ensino brasileiro. No quadro desse artigo, vou levar em conta apenas alguns dos resultados, geralmente pouco utilizados até aqui e que concernem particularmente às respostas relativas às questões mais subjetivas (opiniões, escolhas, preferências, expectativas). Trata-se de questões de escolha única (fechada) sobre os "motivos das escolhas das disciplinas", as "preferências para as disciplinas profissionais ou acadêmicas", as "opiniões sobre a oferta de ensinos da UFRN", a "imagem da UFRN como universidade" e as "expectativas em relação às formações escolhidas".

Meu objetivo com o tratamento das respostas dos candidatos é a análise das diferenças entre as opiniões ou entre as práticas, ou colocar em 
evidência as diferenças entre as posições individuais. Outra proposição, a teoria do "núcleo central" (ABRIC, 1994), fala de cognições constitutivas de uma representação que estão organizadas ao redor de um "núcleo central" que determina suas significações e a natureza de suas relações. Assim, há a ideia de um espaço de consenso (sistema central), no qual uma representação é um conjunto compartilhado de crenças em torno de um núcleo comum, o qual define tanto a identidade como a homogeneidade de um grupo social (RATEAU, 2004). Outro espaço, onde se encontram eventualmente mais divergências interindividuais é chamado de sistema periférico. Então, para a teoria do núcleo central, o importante é descobrir o que "junta" os membros de um dado grupo, e, para a teoria dos princípios organizadores, é revelar os princípios a respeito dos quais eles divergem.

Os dados do vestibular são numerosos, especialmente aqueles relativos às questões de representações da UFRN, sobre a sua imagem, os cursos e as escolhas de disciplinas. Eles nos permitem explorar as diferenças nas respostas entre os candidatos, especificamente entre os candidatos oriundos dos estabelecimentos públicos do ensino médio no Rio Grande do Norte. Com os dados da enquete feita em vinte estabelecimentos públicos, a amostra distinguiu bem duas subpopulações: aqueles que fariam o vestibular da UFRN (do ano 2009) e aqueles que não iriam se candidatar. Uma distinção central para o nosso objetivo que é o de melhor compreender o "desencantamento" entre os estudantes, o desinteresse pela continuação dos estudos no ensino superior.

Muitas questões abertas e fechadas estruturam o questionário que tinha como primeiro objetivo conhecer melhor os estudantes dos anos finais do ensino médio público. Uma questão mais específica foi objeto de uma exploração a respeito da problemática das representações sociais. Naquela relativa à escolha de se candidatar ao vestibular da UFRN, a questão era dirigida a todos os estudantes dos anos finais antes do vestibular naquele ano foi assim formulada: "[...] dê três motivos para a sua escolha de se candidatar para entrar na UFRN." As respostas foram dadas em geral sob a forma de três frases construídas, com o mínimo de três palavras cada.

As duas subpopulações da enquete foram identificadas e diferenciadas segundo seus perfis das respostas às questões fechadas e geralmente com respostas únicas. Como relacionar as características de seus perfis e do que eles dizem a respeito da UFRN? Alguns dos estudantes escolheram se candidatar (um quarto deles), tendo a maior parte respondido que não faria o 
vestibular, mas eles nos deram de qualquer forma uma resposta sobre os "motivos" que os incitaria a entrar na UFRN. Candidatos e não candidatos nos dizem a mesma coisa?

Os resultados foram utilizados e confrontados àqueles tirados do tratamento da principal questão aberta, pivô das interrogações desse artigo: como está organizado o campo representacional da escolha pela UFRN, do que nos dizem os estudantes do ensino público? Procuram-se nos resultados e na centralidade dos elementos da representação social da universidade, as pistas que nos ajudariam a compreender melhor o que acontece no percurso final do ensino médio público, para que os estudantes escolham ou não de prosseguir no ensino superior na UFRN. E as respostas dadas a propósito da escolha da UFRN seriam suficientes para identificar e definir entre os estudantes as representações sociais da universidade em geral, da educação superior e da UFRN? Através dos elementos dessa representação se pode observar "correspondências" ou avançar outras razões diferentes daquelas evocadas anteriormente?

A situação geral do ensino médio público e o desinteresse de uma grande parte dos alunos em prosseguir os estudos no ensino médio foram as 18 manifestações mais visíveis na enquete, assim como os diversos elementos quanto ao modo de estudar, de se informar a respeito da UFRN. Essa relação aos estudos descritos a partir da autoavaliação de suas competências, práticas e o papel do meio familiar, encontramos nos elementos das representações uma correspondência que explicaria as coerências, as lógicas de decisão dos alunos de se candidatar ou não ao vestibular da UFRN?

conjunto das respostas abertas da enquete passou por uma etapa exploratória de um tratamento estatístico Classificação e Análise Fatorial Das Correspondências Múltiplas (AFCM). Retomei, então, os principais resultados das respostas à questão aberta sobre a escolha da UFRN a fim de afinar meu encaminhamento, à procura de "núcleos de sentidos" ou de princípios organizadores, geradores de diferenças definidoras, de acordo com os teóricos das representações sociais e que podem ser esquematizadas na figura seguinte (PIASER, 1999; NETTO, 201 1): 


\section{Teorias das representações sociais}

\section{Teoria do Núcleo Central}

Teoria dos Princípios Organizadores

1: Identificação do conteúdo da representação

2: Estudo das relações entre elementos, de sua importância relativa e absoluta

3: Determinação e controle do núcleo central

1: Atualização de um saber comum

2: Atualização dos princípios organizadores de posições individuais em relação aos pontos de identificação desse saber comum

3: Determinação das ancoragens das posições nas realidades sociopsicológicas

Em muitos dos trabalhos consultados, as metodologias associadas a essas duas grandes correntes teóricas aparecem geralmente como complementares, alguns tentando articulá-las (TAFANI, BELLON, 2003). Na teoria do "núcleo central", a propósito da qual Moliner, Rateau e Cohen-Scali (2002) definem uma abordagem consensual das representações sociais, vejo um parentesco com a abordagem "frequentista" da análise estatística, na qual se trata de encontrar as respostas comuns, coletivas, mais destacadas e mais conexas. Enquanto as técnicas de análise utilizadas por Doise, Clemence e Lorenzi-Cioldi (1992) são técnicas fatoriais fundadas sobre a análise das diferenças interindividuais (destaque para as divergências). Nessa segunda abordagem, uma perspectiva mais "intuicionista", o que obriga o pesquisador a ser mais nuançado e plural diante de uma realidade social complexa e multidimensional. Isso parece mais relacionado com a natureza dos dados recolhidos na nossa enquete e com o fato que foram utilizados como em uma análise secundária ex post. A familiaridade e experiência com as análises multidimensionais me levaram para o lado da teoria dos princípios organizadores:

Os sujeitos não compartilhariam (ou não somente) um referencial categorial comum, mas (igualmente) funções de tratamento da informação implicando diferentes critérios de recorte, de ordenamento e de orientação dos elementos do campo (DOISE, CLEMENCE, LORENZI-CIOLDI; 1992, p. 57-58).

Concretamente, meu encaminhamento se desenvolveu da seguinte maneira: com a classificação descendente hierárquica (CDH) sobre o conjunto dos 1903 estudantes, o procedimento do programa reteve 1761 unidade de 
contexto iniciais (UCi), a classificação das unidades de contexto elementar baseia-se no paradigma algorítmico (UCE) desenvolvido por Max Reinert, que permite separar globalmente classes de unidades de perfis contrastantes. Esse modo de cálculo é útil para discriminar globalmente mundos lexicais, e os laços entre formas específicas não podem ser apreciados senão de maneira abrangente.

A análise fatorial das correspondências permite visualizar as formas com as "contribuições" mais significativas aos dois primeiros eixos principais, que representam mais da metade da inércia total (informação ou variância), é uma aproximação satisfatória. Encontra-se igualmente disposta ao longo desses dois eixos principais a organização dos "campos representacionais" ligados à escolha de entrar na universidade, campos que iremos definir com a operação de interpretação que nos indicam os conteúdos das classes e suas configurações.

Nomeei a Classe 1, a universidade, a UFRN, a universidade pública, "Contexto Universidade" - mais de um quarto do vocabulário desta classe está articulado ao redor da palavra "universidade", ela reagrupa todas as palavras, segmentos que acompanham "universidade" nas respostas. Essa classe cons20 titui a dimensão da esfera "intelectual" dos estudos. A representação gráfica (AFCM) permite situar ao longo do primeiro eixo horizontal, as palavras do vocabulário que caracterizam esse polo "intelectual", a relação com os estudos, na qual se exprimem dois tipos de enunciados que se poderia interpretar como "motivações mistas" e sinais de tensão acerca da UFRN.

Tem-se de um lado, com as coordenadas negativas das palavras refletindo sentimentos de ações mais pessoais: "formar-se, conseguir, ampliar, conquistar"; e, por outro lado, os adjetivos qualificativos de "prestígio, gratuito, reconhecido, qualidade, bom, ótimo", ligados à instituição, a estrutura, o curso, os ensinos, a disciplina de estudos. A universidade, UFRN, que é uma universidade federal, pública, prestigiosa, reconhecida, renomada, a "melhor das universidades", com o ensino de boa qualidade, seus professores competentes. 


\section{Análise Fatorial das Correspondências Múltiplas (AFCM) $F 1=32,4 \% ; F 2=22,3 \%$}

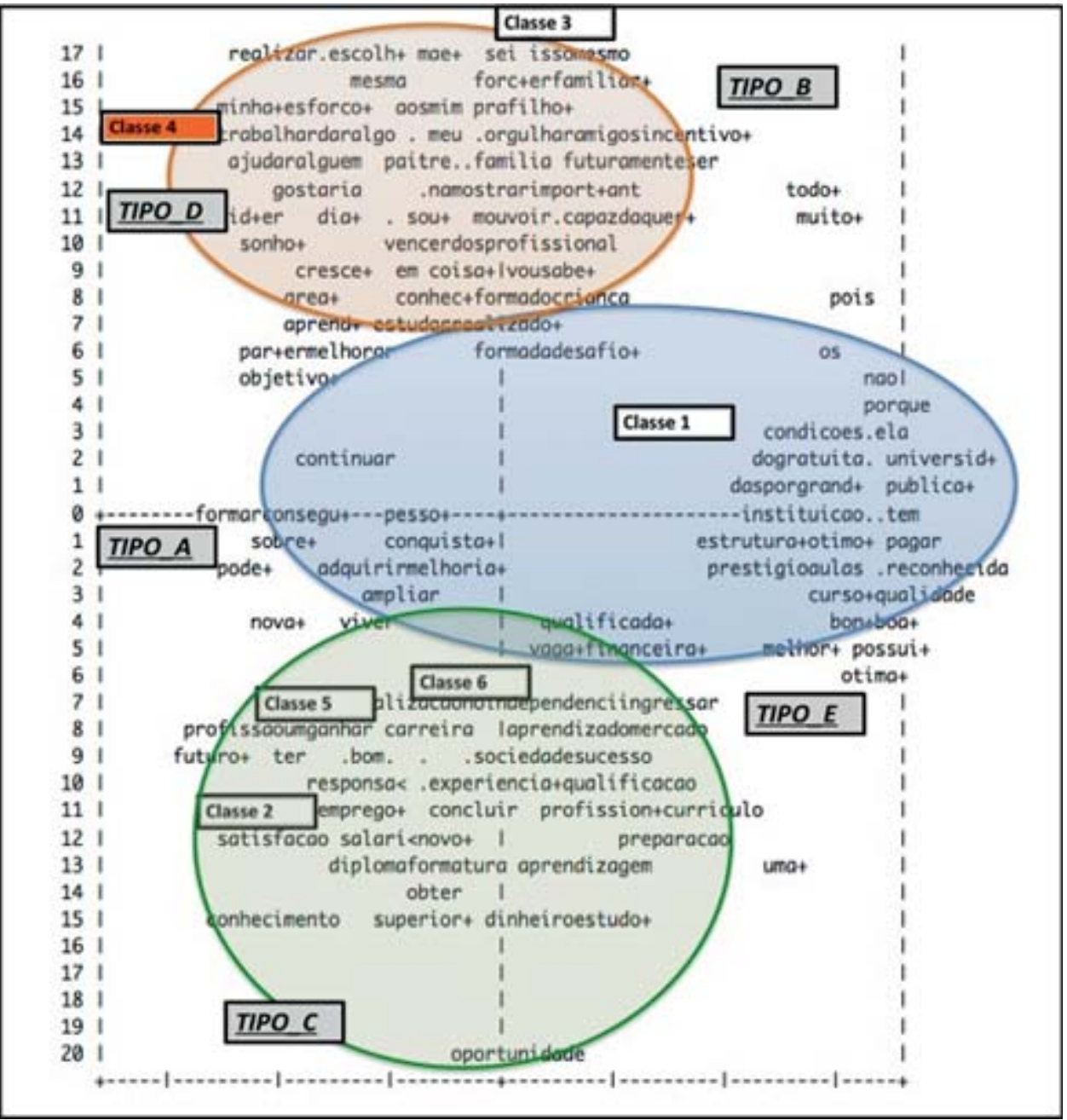

Legenda | Classe = Os círculos que rodeiam as classes e os "vocabulários" ilustram os reagrupamentos, como a Classe 3 que se pode observar no segundo nível da partição da CDH acima.

Legenda | Tipo = Tipologia criada a partir de uma AFCM (no sentido de um "tipo-ideal" weberiano) - perfis dos candidatos e não candidatos para ingressar na UFRN pelo vestibular de 2009, Amostra de 1903 alunos de escola pública com 27 variáveis da enquete, da qual os resultados foram expostos anteriormente. 
A forma "por ser" nas frequências de segmentos repetidos acentua essa forma quase absoluta dos "superqualificativos", "superlativos" amplificando a universidade pública em geral no Brasil e a de Natal para o Nordeste. É preciso lembrar que o estado do Rio Grande do Norte faz parte de uma das regiões "desfavorecidas" da federação. E, destacando sua gratuidade e excelência, os respondentes destacam as tensões com as outras universidades privadas e pagas, geralmente julgadas como não muito boas. Estamos diante de uma população de alunos do ensino público, na qual a grande maioria pertence às classes econômicas e sociais mais baixas /Classes E/D e a C, baixa classe média, segundo nossos critérios de construção de categorias socioeconômicas compostas).

\section{Vocabulário Específico da Classe 1 - UNIVERSIDADE}

Federal + (92), curso + (100), das (37), do (89), ensino + (121), estrutura + (25), faculdade $+(49)$, não (54), ótimo + (52), por (106), porque (44), professor + (72), pública + (42), qualidade (71), tem (59), universid + (190), bom + (27), pagar (22), particular + (18), boa + (69), Brasil (13), condições (24), ela (16), estado (16), ótima $+(30)$, prestígio (17), grande $+(25)$, os (35), aluno $+(14)$, conceituada (10), conhecida $+(13)$, melhor $+(132)$, mensalidade $+(9)$, nordeste (9), norte (8), rio (8), RN (1 1), uma + (172), Natal + (10), pois (13), acho (6), aulas (7), custo $+(5)$, elevado (6), gratuita (9), gratuito (5), instituição (9), já (6), muito $+(35)$, oferecido $+(6)$, paga (7), possui $+(8)$, questão (6), reconhecida $(13)$, referência $+(5)$, são $(6)$, todo $+(13)$, variedade $+(5)$, alto $(7)$, por + ser (13), competente (4), considerada (4), excelente + (17), falada (4), lugar + (6), nenhum (4), nome (5), oferece $+(7)$, passar (10).

Em outros termos, no conjunto das respostas para a questão que solicitava três motivos relativos à escolha de querer entrar na UFRN, se pode ver nesse primeiro "núcleo de sentido" a "Universidade" como a representação ideal do que é uma universidade para os alunos que terminaram o ensino médio: tanto uma estrutura de renome como de ensino de qualidade e gratuito (em oposição às instituições privadas e pagas). Pode-se, então, identificar nessa primeira classe, uma dimensão "Universidade" em uma lógica coerente e bastante homogênea e fortemente relacionada aos estudos (disciplina de estudos, ensino, curso, professores).

A análise e interpretação dos vocabulários específicos de cada Classe com a leitura dos quadros e gráficos da Análise Fatorial das Correspondências 
Múltiplas (AFCM) utilizam, igualmente, outros critérios e elementos suplementares. A visualização desses pontos sobre a carta fatorial nos guiam para definir com as Classes os agrupamentos induzidos pela classificação refazendo na reunião, inicialmente "Emprego" (Classe 2) e "Mercado de Trabalho" (Classe 6), em seguida, "Profissão" (Classe 5), expectativas plurais diante da UFRN para obter um diploma de formação e a escolha de uma profissão. Se a primeira dimensão definiu a relação com os estudos, essa segunda dimensão definiu uma relação com a profissão.

A Classe 2 (EMPREGO), a Classe 6 (MERCADO DE TRABALHO) e a Classe 5 (PROFISSÃO), reagrupam conjuntos de vocabulários específicos que permitem de se projetar no futuro, em relação com a esfera socioprofissional muito pragmática e que justamente a escolha de entrar na UFRN deveria permitir a entrada no mercado de trabalho com uma formação profissional, bons conhecimentos (currículo), um diploma, uma profissão, um bom emprego, uma carreira e sucesso financeiro. Os vocabulários dessas três classes dão uma visão das finalidades bem pragmáticas dos estudos na relação com a profissão. A Classe 5 se situa entre as Classes 2 e 6, compreendendo os elementos próprios à carreira profissional a se concretizar graças à boa qualificação da UFRN, à procura de uma estabilidade, de uma independência. Na Classe 2, ao oposto em relação à Classe que os reúne (Profissão) se dispõe tudo que faz referência ao ingresso no mercado de trabalho, situado mais próximo da origem dos eixos, indicando com isso um perfil mais próximo do perfil médio, da maioria. É no sentido de uma lógica utilitarista, que seria a dimensão utilitária dos estudos na UFRN, que pode ser lido como a articulação dos conteúdos das três classes.

\section{Vocabulário Específico da Classe 5 - Profissional/Carreira}

Carreira (36), estabilidade (20), formação (62), independência (1 1), profissão + (102), qualificação (31), realização (38), sucesso (25), pessoa + (27), aumentar (5), estável (8), financeira $+(18)$, ampliar (5), aprendizado (8), busca (4), conquista + (7), graduação (4), melhoria+(6), satisfação (6), vocação (4), amor (3), financeiro + (4), seguir (6), tornar (4), amizade + (4), capacitação (4), buscar (3), garantia (2), intelectual (2), através (2), chegar (2), academi < (2) 


\section{Vocabulário Específico da Classe 2 - Emprego}

Bom (130), conhecimento + (140), emprego + (126), futuro + (143), ter (182), um (222), profissão (78), diploma (28), superior + (48), responsa $<(9)$, salari < (12), dinheiro (15), experiência + (14), formar (46), novo + (12), obter (18), adquirir (20), aprendizagem (9), arrumar (6), avançado + (5), concluir (7), concurso + (5), consegu+ (24), digna (7), estudo + $(41)$, formatura (6), ganhar (10), oportunidade + (36), pode + (15), sociedade (8), alcançar (7), desenvolver (4), futura + (4), independente (5), nível (18), promissor + (7), garantido (10), gost + (3), maior + (10), profissionalizar (1 1), terminar (6), gosto $+(18)$, sair (4), garantir (7).

\section{Vocabulário Específico da Classe 6 - Mercado Trabalho}

Ingressar (15), mercado (68), no (49), trabalho + (88), curriculums (5), qualificada $+(3)$, vaga $+(4)$, preparação (4), viver (3), acredito (2), conquistar (3), desejada (1), pensar (2), chance (4), conhecido $+(2)$, mundo (2), preparar $+(3)$, social (1), dedicação (2), desenvolvimento (1), num $+(2)$, profissionalização (1), escolhido (2), por ter (1), capacitado (1), facilidade (1), ficar (1), informações (1), preparado (1), reconhecido (2), valor + (1);

Na Classe 3: Pessoal/Família, reagrupa um vocabulário mais específico à vida pessoal e familiar dos jovens que frequentam a rede pública. As expressões estão fortemente ligadas por implicações muito pessoais (pronomes: meus, meu, minha, com a família e consigo mesmol e dá assim um sentido afetivo à escolha de entrar na universidade. É como se, através dessa escotha pessoal, toda a família e os amigos fossem ingressar na UFRN. Também há os sinais de uma vontade de concretizar seus sonhos, seus engajamentos, claro que os esforços para realizá-los, mobilizando as suas capacidades para responder aos desejos da família ou para ajudá-la financeiramente no futuro, com os recursos de uma profissão que a universidade vai permitir. $\bigcirc$ apoio dos próximos e dos amigos também é invocado em certas respostas. 


\section{Vocabulário Específico da Classe 3 - Pessoal/Família}

Meus (66), pais (35), ajudar (30), aos (1 1), dar (20), família (59), filho + (12), meu (60), mim (27), minha + (79), orgulho (33), pra (21), vontade (29), dos (20), sonho + (49), forçar (10), familiar + (14), exercer (7), interesser (9), pagar (5), ajud + (7), amigos (8), amo (5), da (27), futuramente (7), mãe + (10), melhorar (10), mesma (8), quero (25), parar (48), sentir (4), importante (7), apoio (4), ensinar (3), esforço + (8), faz (4), felicidade (4), física (4), incentivo $+(5)$, isso (5), mesmo (5), motivação (3), objetivo $+(13)$, orgulhar (6), pro (4), própria (4), sabe + (7), vale + (4), educação (4), esta (3), meta $+(4)$, outro + (5), primeiro (3), quem (5), tenho (12), desejo (7), penso (2), potencial (2), vai (4)

A Classe 4 tem um vocabulário totalmente voltado para a ação e o investimento individual nos estudos, como uma demonstração de uma autoafirmação que se tem sobre as capacidades esperadas ou que se vai adquirir saberes, conhecimentos, para aprender a estudar, trabalhar, "crescer", progredir e vencer, tornar-se alguém. Encontrar em si as forças para realizar seus sonhos, vencer através do esforço, uma vontade de se realizar a fim de responder aos desejos da família ou de ajudá-la no futuro, enfim, ter melhores condições de vida.

\section{Vocabulário Específico da Classe 4 - Aprender/Crescer/Conhecimentos}

Sou + (15), vid + ver (81), alguém (40), aprend + (40), área + (23), coisa + (18), conhec + (17), cresce + (34), em (39), estudar (37), na (95), profissionalmente (19), vencer (17), capaz (1 1), mostrar (1 1), ser (85), cada (6), quer $+(16)$, criança (6), diferente + (5), escolhida (6), formada (8), gostaria (6), realizar (18), trabalhar (1 1), vou (1 1), sobre + (1 1), casar (4), algo (5), aprovado (4), continuar (5), desafio + (8), desde (3), dia + (8), dizer (4), escolh $+(14)$, financeiramente (5), formado (6), gostar (4), mudar (3), nova + (9), realizado $+(6)$, sei (6), vez $+(4)$, algum $+(4)$, bastante (7), enfermagem (2), especializar (4), estudando (3), inteligente (2), prazer (2), nas (3), parar (3), toda $+(4)$, vestibular $+(5)$, mas (3), ver $+(2)$, subir (2), aprimorar (2), até (2).

segundo fator da análise fatorial $(22,3 \%$ de inércia) tem fortes contribuições com elementos que podem formar outra dimensão da centralidade da representação. Diante da abundância "polissêmica" levantada (veja-se 
os detalhes na sequência dos quadros dos vocabulários das classes), a leitura sobre as "proximidades" das projeções dos elementos suplementares no mesmo plano fatorial vão diferenciar os candidatos dos não candidatos e assim nuançar as características destacadas anteriormente, a propósito da dimensão pragmática dos estudos e a lógica utilitarista dos estudos.

Os posicionamentos dos pontos suplementares ilustrativos, os "tipos" (tipos ideais no sentido weberiano), que são aproximações de perfis desenhados pelas modalidades de muitas variáveis (trinta) descritas anteriormente é notável quanto à coerência observada na distribuição desta tipologia entre candidatos e não candidatos. Os candidatos ao vestibular são mais numerosos entre os tipos "B" e "E" e menos presentes nos outros tipos. Assim, a AFCM permite não somente identificar as linhas de força opondo as tomadas de posição dos indivíduos, mas igualmente de traduzir mais minuciosamente o sentido que eles dão aos itens escolhidos em função de sua ancoragem no campo considerado - quer dizer, em função dos parâmetros sociais, econômicos, profissionais que os caracterizam? (BATAlLLE, 2007).

Assim, ao longo do eixo vertical se perfila outra dimensão em uma lógica igualmente utilitarista, mas diferente daquela definida precedentemente 26 com as classes 2,5 e 6 , são expectativas tanto mais individuais como também mais personalizadas com as relações familiares que se afirmam na relação com os estudos. Os conteúdos da classe 4 se aparentam a definição inicial de um projeto de estudos e de um projeto de vida. É notável que em relação com o nosso questionamento relativo ao que diferenciaria candidatos e não candidatos ao vestibular, os posicionamentos sobre a carta fatorial dos "tipos" onde se tem mais probabilidades de encontrar os candidatos são os tipos " $E$ " e "B".

\section{O campo representacional da UFRN nas respostas dos candi- datos e não candidatos ao vestibular}

As configurações observadas "moveram-se" em relação à precedente sobre o conjunto da população, as Classes são mais reduzidas e estão "dispostas" com algumas diferenças destacáveis em suas "recomposições". É o que no revela a arborescência da classificação CDH le as CAH, Classificação Ascendente Hierárquica, na ideia de classificação dupla). 


\section{AFCM das Classes e dos Vocabulários Específicos das Respostas dos Candidatos do Vestibular 2009 (F1 43\% / F2 30,4\%)}

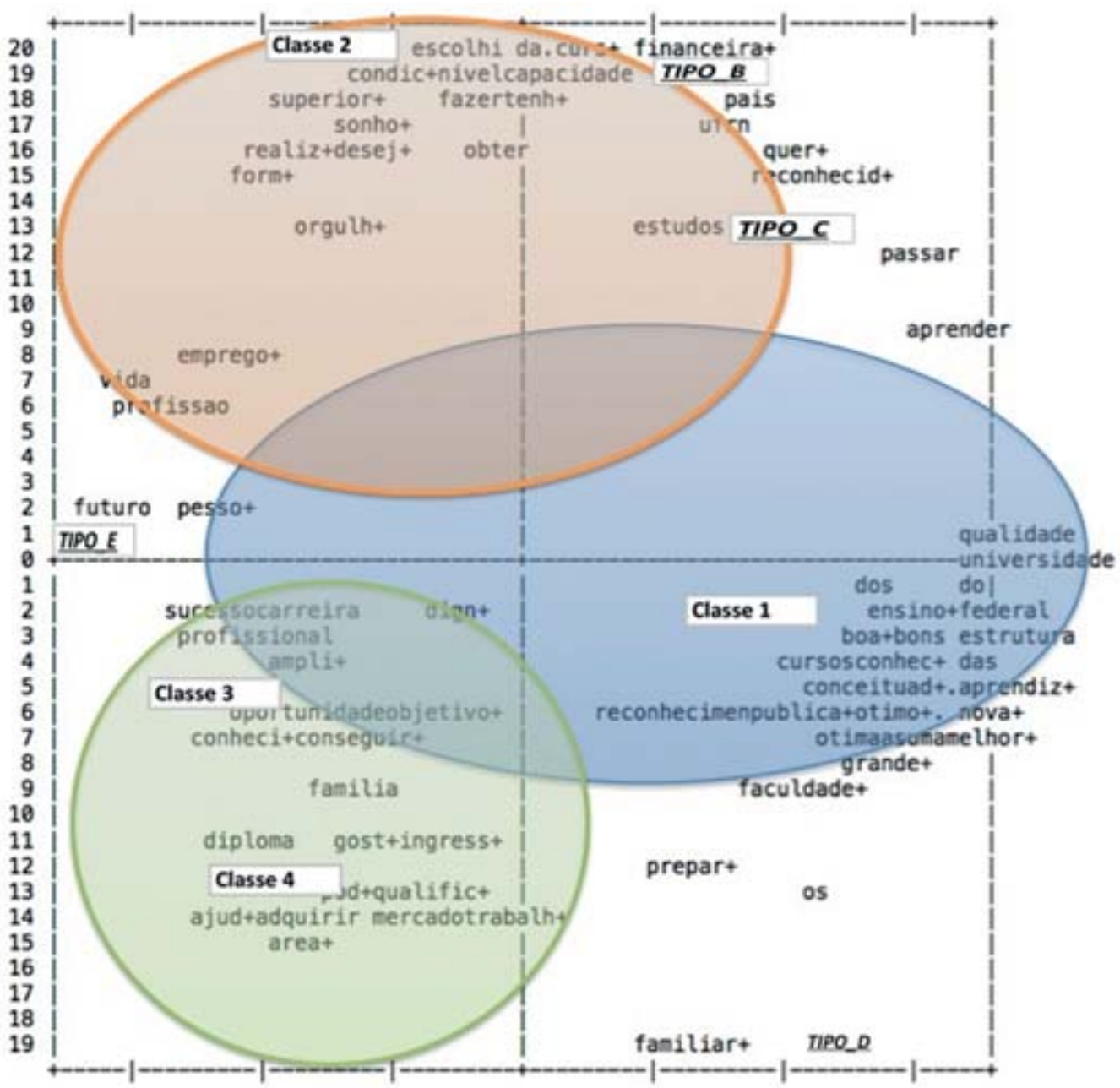

Legenda $\mid$ Classe = Os círculos que cercam as Classes e os "vocabulários" ilustram os reagrupamentos, que se pode observar no segundo nível da partição da CDH acima. Legenda | "Tipo"= tipologia criada a partir de uma AFCM - Perfis dos candidatos à UFRN no vestibular 2009 lamostra de 448 alunos dos estabelecimentos públicos de Natal, com uma enquete de 27 variáveis, da qual os resultados estão expostos acima). 
universo semântico dos candidatos compreende 786 "formas" distintas (53\% do total); o número de Classes estabilizadas se eleva a quatro, ou seja, duas Classes de menos que para o conjunto (1903). A Classe 1 "Universidade" reúne 30\% das unidades classificadas e se demarca sempre muito das outras classes, aparecendo de forma isolada. A redução do número de ramificações - inicialmente nomeei a parte terminal delas -, com a leitura dos "vocabulários específicos" em uma segunda bifurcação pode-se distinguir a Classe "Pessoal/Profissão" (26\%) que se destaca. Enfim, as Classes 3 "Emprego/Conhecimentos/Carreira" (18\%) e 4 "Mercado de Trabalho / Família" (14\%) formam juntas as últimas ramificações. Uma primeira comparação entre os dois "corpus" e suas "Classes" mostra que a redução em número los candidatos inscritos no vestibular representam somente 25\% da nossa amostra) se acompanha de algumas mudanças na "centralidade" dos conteúdos dos vocabulários específicos das Classes. Ao longo do primeiro eixo da AFCM (43\% inércia) a contribuição da Classe "Universidade", a UFRN, como elemento central apareceu mais marcada que sobre a primeira figura, a temática fica ao redor dos seus ensinos e dos seus professores, os dois julgados de qualidade, melhores, ótimos, excelentes, prestigioso. As formas associadas e

28 os segmentos repetidos desse contexto "Universidade" vêm reforçar esse forte reconhecimento da UFRN acerca dos seus ensinos e de seus professores.

\section{Vocabulário Específico da Classe 1 - Universidade}

Universidade $+(68)$, do (37), federal (37), professor $+(22)$, pública $+(21)$, cursos (19), das (19), conceituad $+(8)$, ensino $+(34)$, estrutura (10), melhor $+(18)$, ótimo $+(17)$, prestígio (8), qualidade (22), aluno $+(6)$, Brasil $+(7)$, grande $+(9)$, gratuit $+(7)$, nordeste (6), pag $+(6)$, renom $+(5)$, uma (61), as (6), bons (8), conhecida (4), considerada (4), elevado (4), ótima (10), entrar $(3)$, os (8), profissionais (5), boa $+(17)$, conhec $+(2)$, interess $+(2)$, maior (2), prepar $+(9)$, academic $+(2)$, ao (4), aos (1), aprender (2), aprendiz + $(1)$, conclu $+(3)$, dedic $+(2)$, dos (4), escolh $+(2)$, exercer (2), familiar $+(3)$, important $+(3)$, incentivo $+(3)$, nova $+(1)$, passar (5), possibilidade $+(3)$. 


\section{As formas associadas ao Contexto da Classe 1 - Universidade}

A6 universidade +: universidade (66), universidades (9); $A 7$ do: do (40); A7 federal: federal (3 1); A7 professor +: professor (1), professores (21); A7 pública +: pública (19), públicas (2); A6 cursos: cursos (20); A6 das: das (19); A5 conceitua d +: conceituada (7), conceituadíssima (1); A5 ensino +: ensino (35), ensinos (1); A5 estrutura: estrutura (10); A5 melhor +: melhores (18); A5 ótimo +: ótimo (3), ótimos (8); A5 prestígio: prestígio (8); A5 qualidade: qualidade (22); A4 aluno +: aluno (3), alunos (4); A4 Brasil +: Brasil (6), brasileiro (1); A4 grande +: grande(8); A4 nordeste: nordeste (6); A4 pag+: paga (2), pagar (3), pago (1); A4 uma: uma (79); A3 as: as(7); A3 bons: bons (8); A3 conhecida: conhecida (4); A3 considerada: considerada(4); A3 elevado: elevado (4); A3 ótima: ótima (10).

A centralidade da Classe 1 do contexto "Universidade" se afirma acerca dos elementos mais "estruturantes". O contexto "Universidade" é, de início, associado à Região Nordeste e com o ramo Cursos (disciplinas, ensinos), a partição da arborescência engloba o conjunto dos elementos, a UFRN é qualificada pelos seus ensinos (disciplina escolhida para o concurso que é mais ou menos seletiva). Então, é a relação com os estudos que vem primeiro. segundo elemento maior da estrutura é justamente a "Estrutura", a UFRN é uma estrutura de ensino (no sentido de instituição) de qualidade, que faz de seus estudantes bons profissionais, graças aos seus excelentes professores.

Essa visão estrutural de um conjunto hierarquizado, a Classe 1 do contexto "Universidade", designa, naturalmente, um núcleo ou sistema central da representação social da UFRN como polo intelectual pelos candidatos do vestibular (2009). A UFRN é a estrutura apropriada para as finalidades intelectuais dos estudos. Em relação ao conjunto da população da enquete, entre os candidatos, isso está mais concentrado ao redor da estrutura da universidade e dos seus ensinos.

Lendo os perfis das duas subpopulações, a propósito notadamente das respostas dadas quanto à pesquisa de informações e conhecimentos sobre os ensinos, o fato mais significativo pode ser observado entre os não candidatos. Eles não se informam e conhecem menos ainda as disciplinas de estudo e os ensinos da UFRN. Enquanto que entre os candidatos encontram-se as respostas que se poderia esperar, isto é, os sinais claros de uma mobilização. Aquele que diz "não estar preparado" tem três vezes menos chances do que 
aquele que se diz preparado para se candidatar ao vestibular - é a estimação do modelo e não uma observação.

Com o segundo fator da AFCM, mais de 30\% da inércia lbastante próxima do primeiro 43\%), se observa ao longo do eixo vertical (de baixo para cima) no plano fatorial, de um lado a Classe 4 (Contexto "Mercado do Trabalho - Família") e a Classe 3 (Contexto "Emprego, Conhecimento, Carreira"), em uma configuração que se situa ao oposto com a Classe 2 (Contexto "PessoalProfissão"). $\bigcirc$ contexto da Classe 4 articula, de um lado, um polo representado por verbos ativos no quais domina aquele de "poder" trabalhar, amar trabaIhar, entrar no mercado de trabalho e, por outro lado, a família que aparece no centro dos objetivos de suas ações. E são quase essencialmente para objetivos que tratam da família: poder ajudá-los, poder dar prazer para a sua família, poder constituir uma família [...] E, entrar no mercado de trabalho significa aqui poder trabalhar para realizar um projeto pessoal que faz uma forte referência à família de forma, talvez, a não ter que depender dela ou desobrigá-los de um "fardo".

Na Classe 3, o contexto "Emprego/Conhecimento/Carreira" é mais centrado sobre "como conseguir a ter" um emprego que é o objetivo, é preciso 30 o diploma para aproveitar as oportunidades e "aumentar" seus conhecimentos para que a carreira profissional seja um sucesso. Logo, as Classes 4 e 3 são dois subconjuntos que organizam as expectativas profissionais com a passagem pela UFRN. O emprego é, antes de tudo, entrar no mercado de trabalho com preocupações ligadas à família, o que é geralmente apresentado em filigrana no projeto de vida. É também um princípio organizador muito pragmático e realista, quando são evocados com a ideia de aumentar os conhecimentos, como garantia de acesso ao emprego. Provavelmente, os conhecimentos aprendidos, no ensino médio, não são julgados como satisfatórios e se considera que a universidade vai poder resolver o problema dessas lacunas.

Enfim, ao contrário do alto do eixo do segundo fator, a Classe 2 é uma concentração de expressões e de vocabulário traduzindo uma real mobilização individual para o "alto nível", é uma afirmação muito pessoal do projeto de vida pessoal ligado a uma profissão vista como um "sonho", porque isso foi desejado desde muito tempo. Há orgulho, vontade, desejo de reconhecimento, aliados a uma vocação que, juntos, desempenham um papel na escolha dos 
cursos de estudo. A relação com os estudos e com a profissão faz parte de um projeto pensado há muito tempo, com uma esperada grande valorização social e financeira. As visões pessoais e as visões profissionais estão juntas em vista de uma posição profissional superior.

Como para os subconjuntos precedentes, a Classe 2 remete à finalidade pragmática dos estudos, com a diferença que destaca um aspecto importante quanto à escolha da UFRN. Esses candidatos parecem ter um firme projeto individual de formação e a relação com os estudos e a profissão futura estão estreitamente ligados. Enquanto, para os candidatos das Classes 3 e 4, as finalidades pragmáticas dos estudos parecem divididas entre os conhecimentos não adquiridos no ensino médio e as preocupações diante da família a ajudar ou a iniciar.

No perfil dos candidatos tomados isoladamente, destaca-se também a observação que, em um conjunto de 25 variáveis, o bloco referente às modalidades das questões sobre a família (em número de 4): seu papel na preparação, sua influência na escolha da UFRN, ter alguém próximo que estudou na UFRN, estão bem "isoladas" das outras variáveis. A família está presente, aporta sua ajuda e é significativa em um caso bem preciso: quando o candidato tem um parente ou um próximo que estudou na UFRN ( 100 casos sobre 448).

Senão, para a maioria dos candidatos a ajuda familiar é pouco presente. Uma "atração" muito significativa entre as escolhas por vocação, formação profissional, conhecimentos e pesquisa, orienta-se no sentido de uma escolha pensada e construída há muito tempo (desde o ensino fundamental). Pode-se identificar entre esses candidatos uma grande maioria para os quais as finalidades profissionais, a relação com os estudos e a profissão estão estreitamente associados a uma vocação. E no caso em que a família parece ocupar um lugar mais importante, essas finalidades profissionais aparecem mais associadas às escolhas de melhoria das condições de vida, mercado de trabalho e sucesso financeiro. 


\section{Síntese das AFCM \\ Candidatos e não Candidatos ao Vestibular da UFRN (2009) As Dimensões da Representação Social da UFRN}

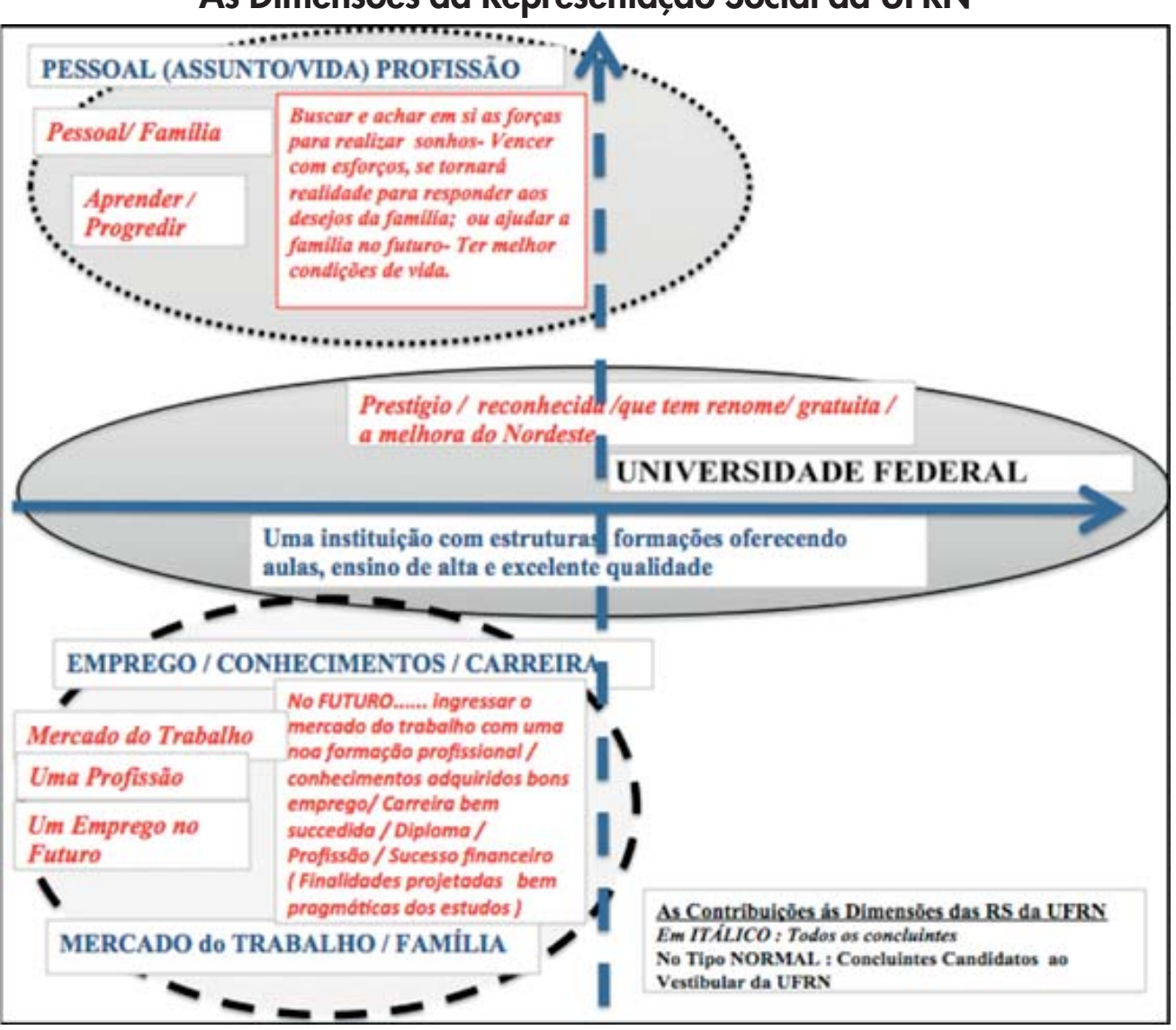

Sobre a carta fatorial acima, retomei e superpus os elementos da AFCM detalhados, mas de forma simplificada. É uma síntese por resumir o essencial dos "núcleos" que definem nesse espaço geométrico (planos e eixos fatoriais 1 e 2) o campo representacional dos motivos de querer entrar na UFRN. A população estudada é aquela dos jovens oriundos dos anos finais do ensino público candidatos e não candidatos ao vestibular 2009. Com cada fator, destaquei os elementos centrais: um sobre o primeiro eixo horizontal a Universidade e dois sobre o eixo vertical, as finalidades socioprofissionais, versus profissão. E as finalidades socioprofissionais versus Emprego e Mercado de 
Trabalho; para a Profissão estaria associado um projeto pessoal e uma relação como os estudos mais vocacional. $\bigcirc$ segundo elemento estaria mais imbricado com a presença da família e uma relação como os conhecimentos, o que traduz certo realismo a esses respeitos em relação com aqueles precariamente aprendidos ou mesmo não adquiridos no ensino médio.

\section{Considerações finais}

Os resultados obtidos, nessas análises detalhadas, dão dimensões às representações sociais da UFRN que se juntam àqueles colocados em evidência anteriormente na análise fatorial dos perfis dos candidatos e não candidatos. Essas análises trazem precisões sobre suas diferenças quanto às respostas dadas sobre a escolha da UFRN. Essas diferenças irão se definir sobretudo na relação com os estudos. As duas análises se associam na interpretação da relação com os estudos. A propósito dos candidatos ao vestibular, uma primeira dimensão está organizada acerca da UFRN, reconhecida principalmente por seus cursos. É o polo "intelectual" bem marcado e esperado na comparação com a relação com os estudos vivida no ensino médio. Uma segunda dimensão organiza o polo "pragmático" da representação da UFRN acerca da profissão futura para a qual o candidato se mobiliza com um forte engajamento individual, com vista ao alto nível sua escolha é feita mais por vocação. Os termos empregados, geralmente, se aparentam com a definição inicial de um projeto de estudos e de vida.

Ao oposto dessa segunda dimensão, uma terceira dimensão pode ser definida entre os candidatos que pertencem igualmente à esfera pragmática, mas que têm uma visão mais utilitarista e oportunista, no sentido que o que aparece mais destacado nas respostas é o ingresso no mercado de trabatho, o emprego e a carreira que depende disso. As preocupações ligadas à família são pregnantes quanto ao futuro. Quanto à relação com os estudos, a presença associada e bastante marcada dos temas fazendo referência aos conhecimentos pode ser interpretada como certa reserva diante daqueles adquiridos no ensino médio.

Essas três dimensões aparecem no conjunto das respostas dos estudantes do ensino médio (candidatos e não candidatos ao vestibular), as diferenças podendo ser observadas nas modificações bem significativas que se operam 
nas configurações das Classes que organizam essas dimensões. Assim, já se pode dizer que, na relação com os estudos, e a primeira dimensão, a universidade como polo intelectual é bem mais estreitamente associada entre os candidatos que entre os não candidatos, entre os quais se insiste mais sobre - lado prestigioso, renomada e reconhecido da UFRN, do que sobre seus cursos, as disciplinas que nela são ensinadas ou seus professores. É importante verificar que eles se distinguem nesse ponto dos estudantes que vão se candidatar ao vestibular.

A diferença mais notável pode ser observada na "dupla dimensão pragmática" da representação: para os candidatos esta emerge nitidamente nos dois polos descritos na configuração apresentada, enquanto para o não candidato, a configuração da segunda dimensão está organizada acerca do emprego, do mercado de trabalho e da profissão. É certamente sua primeira preocupação no momento da enquete e está associada ou organizando a terceira dimensão, que tem uma visão pragmática também com as expectativas individuais, pessoais ou ligadas à família, e uma grande enumeração de atividades "intelectuais" (aprender, progredir, conhecer...) para colocar em ação e atingir os objetivos.

34 Desde logo, posso ver nesse exercício mais que uma similaridade com o pensamento prático que constitui a atividade de representação social, uma "forma intelectual de bricolagem" (LÉVI-STRAUSS, 1962). Na sociologia interacionista da Escola de Chicago o papel das atitudes tem um status teórico muito próximo das representações sociais. Nos escritos de difundidos em nossas pesquisas no Laboratório CRES ${ }^{5}$ por Alain Coulon (1987), os etnométodos são um conjunto de práticas, de rotinas e de procedimentos utilizados pelos indivíduos com o objetivo de dar sentido as suas ações cotidianas, simultaneamente a sua própria realização. Nesse caso, este conjunto remete aos "conhecimentos do senso comum descritível". As passarelas em nosso propósito com os encaminhamentos das abordagens das representações sociais são possíveis quando se pensa nos "etnométodos" do estudante.

Enfim, invocamos brevemente a questão da Orientação, um setor de pesquisas e de estudos bem desenvolvido nos países avançados, mas pouco explorado no Brasil (PAUL; OSTHEIMER-PAUL, 2005). Isso mereceria um pouco mais de atenção da parte dos pesquisadores e dos responsáveis de todos os níveis do sistema educativo, particularmente na transição do ensino médio para o ensino superior. É nesse nível que a problemática das representações sociais 
dos estudos, das universidades, entre outros temas, poderia ocupar um lugar preponderante para um melhor conhecimento dos estudantes que se candidatam à educação superior ou dos novos ingressantes na universidade.

\section{Notas}

1 É preciso salientar a esse respeito que o Inep coloca à disposição do público todos os dados sob a forma de "microdados", mas geralmente é difícil poder extrair os dados de que realmente precisamos. Passa-se muito tempo para encontrar os bons dados no site www.inep.gov.br (microdados).

2 A base de dados do OVEU (Observatório da Vida do Estudante Universitário) da UFRN reúne, em suma, informações que não se encontram em outros lugares, sobre os candidatos e os ingressantes na universidade desde o começo de 2000.

3 Nota sobre as estatísticas: entre esses candidatos, a soma anual do período, há evidentemente contagens múltiplas, isto é, candidatos que fizeram o vestibular por várias vezes.

4 Enquete 2009-2010, dirigida por Betânia Leite Ramalho, com minha participação, no quadro da pesquisa "A passagem do Ensino Médio da rede pública à universidade pública: estudo sobre o acesso e a inclusão na cultura universitária (2004-2010)".

5 CRES-Centre de Recherchesurl'EnseignementSupérieur (Centro de Pesquisa sobre o Ensino Superior), grupo de pesquisa ligado ao CIRCEFT-Centre interdisciplinaire de recherche, culture, éducation, formation, travail (Centro Interdisciplinar de pesquisa, cultura, educação, formação, trabalho) da Université de Paris 8 - Vincennes à Saint-Denis (www.circeft.org), o qual tem um acordo de cooperação com o PPGED-Programa de Pós-Graduação em Educação da UFRN.

\section{Referências}

ABRIC, Jean Claude. Pratiques sociales et représentations. Paris: PUF, 1994.

ABRIC, Jean-Claude. Méthodes d'étude des représentations sociales. Toulouse: ERES, 2003. (Hors collection)

BATAILLE, Michel; MIAS, Christine; PIASER, Alain. Profils étudiants et motivations à l'inscription en master 1 de Sciences de l'éducation: vers une homogénéisation des profils? Actualité de la Recherche en Éducation et en Formation. Strasbourg (França): 2007.

BOUDRENGHIEN, Gentiane; FRENAY, Mariane. La transition de l'enseignement secondaire vers l'enseignement supérieur: Rôle des représentations et motivations à l'égard de son projet de formation. Orientation Scolaire et Professionnelle. (Paris, França) avr./jui. v. 40, n. 2, p. 1-20, 2011. 
BUARQUE, Cristóvão Buarque. A Revolução Republicana na Educação: Ensino de qualidade para todos. São Paulo: Moderna, 2011.

COHEN-SCALI, Valérie; MOLINER, Pascal. Représentations sociales et identité: des relations complexes et multiples. Orientation scolaire et professionnelle. Paris, v. 37, n. 4, Identités \& orientations 2, p. 465-482, 2008.

COULON, Alain. L'Ethnométhodologie. Paris: Presses Universitaires de France, 1987.

COULON, Alain; ENNAFAA, Ridha; PAIVANDI, Saeed. Devenir enseignant du supérieur: enquête auprès des allocataires moniteurs de l'enseignement supérieur. Paris: Budapest: Torino: I'Harmattan-Savoir et formation, 2004.

COULON, Alain. A condição do estudante: a entrada na vida universitária. Tradução: Georgina Gonçalves dos Santos, Sônia Maria Rocha Sampaio. Salvador: EDUFBA, 2008.

DOISE, Wilhem; CLEMENCE, Alain; LORENZI-CIOLDI, Fabio. Représentations sociales et analyses de données. Grenoble: Presses Universitaires de Grenoble, PUG, 1992.

DOISE, Willem. Les représentations sociales. In GHIGLIONE, Rodolphe; BONNET, Christian; RICHARD, Jean-François. Traité de psychologie cognitive. Paris: Dunod, 1990. (Tome III).

36 DORAY, Pierre; BOURQUE, Claude Julie; MASON, Lucia; SZCZEPANIK, Geneviève. Choix professionnel, carriéres scolaires et production de la relève technique. Note de recherche. UQAM, Montréal, CIRST, 2003-2004.

DURU-BELLAT, Marie; KIEFFER, Annick. Du baccalauréat à l'enseignement supérieur en France: déplacement et recomposition des inégalités. Population, Paris, Janvier-Février, mars, v. 63, n. 1, p. 123-157, 2008.

ENNAFAA, Ridha. As desigualdades sociais na educação: o exemplo da educação superior brasileira. Revista Pedagógica, (Chapecó, SC) n. 29, v. 2, p. 155-195, jul./dez. 2012. Disponível em <http://bell.unochapeco.edu.br/revistas/index.php/pedagogicas/issue/ view/104/showToc> Acesso em: 30 ago. 2013

JODELET, Denise. (Dir.) Les représentations sociales. Paris: Editions PUF, 1989.

LÉVI-STRAUSS, Claude. La pensée sauvage. Paris: Plon, 1962.

MOLINER, Pascal. Cinq questions à propos des représentations sociales. Les Cahiers Internationaux de psychologie sociale, (Liège, Bélgica) n. 20, p. 5-14, 1993.

MOLINER, Pascal; RATEAU, Patrick; COHEN-SCALI, Valérie. Les Représentations Sociales: pratiques des études de terrain. Rennes: Editions Pur Didact, 2002. 
MOSCOVICl, Serge; KALAMPALIKIS, Nikos. Une approche pragmatique de l'analyse Alceste. Les Cahiers Internationaux de Psychologie Sociale. Presses Universitaires de Liège. (Liège, Bélgica) maio/juin-Juillet, v. 2. n. 66, p. 15-24, 2005.

PASCOAL, Miriam; HONORATO, Eliane Costa; ALBUQUERQUE Fabiana Aparecida de. $\bigcirc$ orientador educacional no Brasil. Educação em Revista, Belo Horizonte. n. 47, p. 101-120, jun. 2008.

PAUL, Jean-Jacques; OSTHEIMER-PAUL, Maria-Luiza. Le choix d'une profession par les étudiants. Le cas du Brésil. Revue internationale d'éducation de Sèvres. Dossiers: Les défis de l'orientation dans le monde. Sèvres (França) Janvier/Avril, n.38,p.77-86, 2005.

PIASER, Alain. Représentations professionnelles à l'école: particularités selon le statut: enseignant, inspecteur. 1999. 381 p. Thèse (Doctorat en Sciences de l'Éducation) -., Université de Toulouse-le Mirail, Toulouse, 1999.

PIASER, Alain; BATAILLE, Michel. Of contextualised use of "social" and "professional". In CHAÏB, Mohamed; DANERMARK, Berth; SELANDER, Staffan(Eds.). Social Representations and Transformation of Knowledge. London: Routledge, 2011.

RATEAU Patrick, ROUQUETTE Michel-Louis. Introduction à I'étude des représentations sociales. Grenoble: PUG, 1998.

RATEAU, Patrick. Princípios organizadores e núcleo central das representações sociais. Hipóteses empíricas. Arquivos Brasileiros de Psicologia, Rio de Janeiro, v. 56, n. 1, p. 80-90, jan./abr. 2004.

RATINAUD, Pierre. Uma evidência experimental do conceito de representação profissional através do estudo da representação do grupo ideal. Nuances: estudos sobre Educação, Presidente Prudente, v. 16,n. 17, 135-150, 2009.

REINERT, Max. Quelques problèmes méthodologiques posés par l'analyse de tableaux "énoncés $\times$ vocabulaire". Actes des Secondes Journées Internationales d'Analyse Statistique des Données Textuelles, Montpellier, 21-22 octobre 1993/Paris, ENST, 1994.

ROUQUETTE, Michel Louis. Representações e práticas sociais: alguns elementos teóricos. In MOREIRA, Antonia Silva Paredes; OLIVEIRA, Denize Cristina de (Org.). Estudos interdisciplinares de representação social. Goiânia Editora AB, 2000.

SCHUTZ, Alfred. Le chercheur et le quotidien. Phénoménologie des sciences sociales. Paris: Klinksiek. 1987. 
TAFANI, Eric; BELLON, Sebastien. Etudesexpérimentales de ladynamiquedesreprésentationssociales. In: ABRIC, Jean-Claude. Méthodes d'étude des représentations sociales-ERES. Hors Collection, p.255-277, 2003.<http://www.cairn.info/methodes-d-etude-des-representations-sociales-page-255.htm> Acesso em: 30 ago. 2013

TEIXEIRA, Ana Maria Freitas. A universidade entre as palavras de jovens de origem popular. In: SANTOS, Georgina Gonçalves dos; SAMPAIO, Sonia Maria Rocha. Observatório da vida estudantil. Estudos sobre a vida e cultura universitárias. Salvador: EDUFBA, 2012.

ZAGO, Nadir. Do acesso à permanência no ensino superior: percursos de estudantes universitários de camadas populares. Revista Brasileira de Educação, Rio de Janeiro, v. 11 , n. 32, p.226-237, maio/ago. 2006.

Prof. Dr. Ridha Ennafaa Université de Paris 8 | Vincennes à Saint Denis Centre Interdisciplinaire de Recherche Culture, Education, Formation, Travail |

Centre de Recherche sur l'Enseignement Supérieur | CRES E-mail | ridhaennafaa@gmail.com

Tradução | Prof. Dr. Adir Luiz Ferreira Universidade Federal do Rio Grande do Norte Departamento de Fundamentos e Políticas da Educação Programa de Pós-Graduação em Educação Grupo de Pesquisa "Escola Contemporânea e Olhar Sociológico"| ECOS E-mail| adirlfer@gmail.com

Recebido 15 abr. 2014 Aceito 9 jul. 2014 